\title{
Non-typhoidal Salmonella Gastroenteritis in Al Ain Hospital United Arab Emirates
}

\author{
Al-Dhaheri Khawla, A-Sheikh F*, Jaffal A, Hammad M, and Baloushi R \\ Department Microbiology, Institute of Clinical Laboratory Services, Al Ain Hospital, Abu-Dhabi, United Arab Emirates
}

*Corresponding author: A-Sheikh F, Department Microbiology, Institute of Clinical Laboratory Services, Al Ain Hospital, Abu-Dhabi, United Arab Emirates, Tel: 97137022000; E-mail: farrukhaminsheikh@hotmail.com

Rec: Jan 16, 2017, Acc: Feb 16, 2017, Pub: Feb 23, 2017

Copyright: $\odot 2017$ Khawla AD, et al. This is an open-access article distributed under the terms of the Creative Commons Attribution License, which permits unrestricted use, distribution, and reproduction in any medium, provided the original author and source are credited.

\begin{abstract}
Objectives: The purpose of this study was to identify serogroups and antimicrobial susceptibility of non-typhoidal Salmonellas from gastroenteritis patients among out- and in-patient population of Al Ain Hospital in Al Ain, United Arab Emirates during the period of 1st April 2007 to 30th April 2013.

Methods: A retrospective study was carried out through review of the stool specimen record sent for bacteriological culture to Clinical Institute of Laboratory Services at Al Ain Hospital from 1st April 2007 to 30th April 2013. Culture and antimicrobial susceptibility of the isolates were carried out by using standard laboratory procedures. Serotyping was performed using commercial anti-sera.

Results: During the study period of 6 years a total of 205 laboratory confirmed non-typhoidal Salmonellas were isolated from the stool of patients with diarrhea. The majority of these strains $(69 \%)$ was from patients of 0-14 years of age. Salmonella group B was the most frequent serogroup $(36 \%)$ followed by serogroup D $(27 \%)$ and then Salmonella spp. (26\%). Salmonella serogroups A \& C were $1 \%$ and $10 \%$, respectively. The most frequently detected antibiotic resistance was to Ampicillin (25\%), Co-Trimaxazole (15\%) and Chloramphenicol (5\%). Salmonella group B was the most resistant. The majority were, however, susceptible to other drugs with low to very low resistance rates ( $5 \%$ to Ciprofloxacin, and $2 \%$ to Ceftriaxone). Overall, resistant strains were more prevalent among children $(30 \%)$ than adults $(23 \%)$.

Conclusions: Salmonella gastroenteritis is an important clinical condition in children more than in adults In the United Arab Emirates. Salmonella serogroup B, D and Salmonella spp. are prevalent strains causing gastroenteritis. Most of the Salmonella serogroups isolated in this study showed a high resistance to Ampicillin in comparison to other antibiotics. The emergence of resistance against Ceftriaxone among non-typhoidal Salmonella spp. is an alarming sign.
\end{abstract}

Keywords: Gastroenteritis; Ampicillin; Chloramphenicol

\section{Introduction}

The genus Salmonella contains over 2000 different antigenic types [1]. Non-typhoidal Salmonella (NTS) species are important foodborne pathogens with acute gastroenteritis being the most common clinical manifestation [2]. Transmission of Salmonella is generally via the fecaloral route, with infection occurring following the consumption of directly or indirectly contaminated food products [3]. Infection with non-typhoidal Salmonella usually result in an acute but self-limiting gastroenteritis that does not require antibiotic therapy, though in the young, the elderly and the immunocompromised the symptoms may be more severe and can lead to septicemia, arthritis, meningitis and pneumonia [2,4]. Evidence of increasing antimicrobial resistance is of concern when treating Salmonellosis worldwide [5].

Therefore, this study was undertaken to determine the presence of non-typhoidal Salmonella, and their pattern of serogroups and antimicrobial susceptibility among patients suffering from gastroenteritis at the Al Ain Hospital in Al Ain, United Arab Emirates.

\section{Methods}

Al Ain Hospital is a 400-bed tertiary health care centre, situated in the eastern region of Abu-Dhabi in the United Arab Emirates. It is considered a referral centre as well as a primary health care facility. Patients reported with gastroenteritis from April 2003 through April 2009 were identified by review of the clinical stool culture records of the hospital microbiology laboratory. For isolation of Salmonella species, all stool specimens were cultured directly onto Xylose Lysine Deoxycholate (XLD) agar (Medysinal), Deoxycholate Citrate (DCA) agar (Medysinal), and Selenite F broth (Medysinal). After 4 hours incubation, the later was subcultured again onto DCA and XLD. Nonlactose fermenting (NLF) colonies were inoculated in the Urea agar (Medysinal) and Triple Sugar Iron (TSI) agar (Medysinal). After overnight incubation, organisms giving a negative Urea reaction, and positive TSI reaction (Alkaline/Acid $+\mathrm{H} 2 \mathrm{~S}$ ) were further identified by means of API 20E (Analytical Profile Index, Biomeriuex, France), or Vitek II, Biomeriuex, (France). Isolates biochemically confirmed to be Salmonella were serogrouped using specific antisera (MAST Assure).

Antibiotic susceptibility testing was determined by means of KirbyBauer disk diffusion method using the guidelines provided by Clinical Laboratory Standard Institute (CLSI), formerly known as National 
Committee for Clinical Laboratory Standards (NCCLS) guidelines [6]. The antimicrobial agents routinely tested included Ampicillin, Chloramphenicol, Co-Trimaxazole, Ciprofloxacin, and Ceftriaxone.

\section{Results}

Only patients with diarrhea, vomiting or both with loose stools and positive for Salmonella culture were included. Stool samples with positive culture for Salmonella para typhi A, B, C or D were excluded. There were 205 laboratories confirmed Salmonella cases (Table 1). The majority of patients were children $0-14$ years of age (69\%). This was significantly higher compared with the rate for adults (31\%). Male sex predominated 118 (58\%). Two isolates (1\%) were Salmonella serogroup A, 21 (10\%) were Salmonella serogroup C, 54 (26\%) were Salmonella spp. 55 (27\%) were Salmonella serogroup D and 73 (36\%) were Salmonella serogroup B (Table 2).

\begin{tabular}{|l|l|l|l|l|l|l|}
\hline \multirow{2}{*}{ Age group } & \multicolumn{6}{|l|}{ Salmonella Serogroups } \\
\cline { 2 - 7 } & A & B & C & D & Spp & Total \\
\hline $\begin{array}{l}0-14 \\
\text { (children) }\end{array}$ & 2 & 55 & 12 & 33 & 39 & 141 \\
\hline $\begin{array}{l}>14 \\
\text { (Adult) }\end{array}$ & - & 18 & 9 & 22 & 15 & 64 \\
\hline
\end{tabular}

Table 1: Age distribution of 205 patients with gastroenteritis by different Salmonella serogroups.

\begin{tabular}{|l|l|l|}
\hline $\begin{array}{l}\text { Salmonella } \\
\text { serogroups }\end{array}$ & Number Identified & Percentage \\
\hline Serogroup A & 2 & 1 \\
\hline Serogroup B & 73 & 36 \\
\hline Serogroup C & 21 & 10 \\
\hline Serogroup D & 55 & 27 \\
\hline Salmonella sp & 54 & 26 \\
\hline Total & 205 & 100 \\
\hline
\end{tabular}

Table 2: Incidence of Salmonella serogroups isolated from patients with gastroenteritis.

The antibiotic resistance rate (Table 3) was highest with Ampicillin (25\%), followed by Co-Trimaxazole (15\%). Resistance against Ceftriaxone was seen only with Salmonella serogroup B, other groups did not show resistance against Ceftriaxone. One hundred forty six isolates $(71 \%)$ were susceptible to every antimicrobial agent tested. The remaining strains were resistant to one or more of the antimicrobial agents tested. All serogroups show high susceptibility to Ceftriaxone except serogroup B. Overall resistant strains were more prevalent among children (30\%) than adults (23\%).

\section{Discussion}

Non-typhoidal Salmonella represent an important public health problem in many part of the world including UAE. An increase in the incidence of non-typhoidal Salmonellosis has been noted throughout the world [7] and the same trend can be expected in UAE. Another important problem is the increase of antimicrobial resistance in Salmonella, as recently reported by several authors [8,9]. Our study was an attempt to identify the pattern of serogroups and antimicrobial susceptibility of non-typhoidal Salmonellas. A study conducted in Thailand, identified 394 cases of non-typhoidal Salmonella in children [10]. 459 cases were diagnosed in Spain for four years [11]. In Kuwait, 661 strains were isolated in a 3 years period [12]. During a period of 3 and $1 / 2$ years a total of 412 non-typhoidal Salmonella were isolated from children of Saudi Arabia [5]. There were 56,660 reported cases of non-typhoidal Salmonella in California from 1990 through 1999 [4]. There were 136 Salmonella isolates at the Montreal Children's Hospital between June 1, 1971 and June 30, 1972 [13]. Based on the comparison of our data with those from other countries, the UAE seems to be lower incidence of non-typhoidal Salmonella. Only 121 cases were identified in Malaysia during a 4 years study period [14]. Our results indicated that, as expected, in non-outbreak human diarrheal cases the Salmonella strains are frequently present in the stool specimens $(69 \%$ in children and $31 \%$ in adults (Table 1)). A study from Germany found that infants had remarkably higher incidence of Salmonella than adults [15]. Among reported cases in California USA, children had the highest rate compared to adults [4].

\begin{tabular}{|l|l|l|l|l|l|l|}
\hline \multirow{2}{*}{ Agent } & \multicolumn{6}{|l|}{ Salmonella Serogroups (\%) } \\
\cline { 2 - 8 } & A & B & C & D & SPP & Total \\
\hline Amp & - & 46 & 23 & 9 & 12 & 25 \\
\hline C & 0 & 11 & 18 & 0 & 7 & 8 \\
\hline CRO & 0 & 4 & 0 & 0 & 0 & 2 \\
\hline CIP & 0 & 6 & 19 & 2 & 0 & 5 \\
\hline SXT & 0 & 29 & 16 & 6 & 4 & 15 \\
\hline $\begin{array}{l}\text { Amp: Ampicillin; C: Chloramphenicol; CRO: } \\
\text { Ceftriaxone; CIP: Ciprofloxacin; SXT: } \\
\text { Co-Trimaxazole }\end{array}$ \\
\hline
\end{tabular}

Table 3: Resistance pattern of the Salmonella serogroups to different antimicrobial agents.

Most of our isolates were serogroup B, followed by serogroup D and Salmonella spp. A small proportion were serogroups C and A. A study from Thailand showed a similar pattern of distribution in which the majority of isolates were serogroup B (56.1\%) [10]. The most frequent Salmonella serogroup in Spain was serogroup D [11]. In Taiwan, serogroup D formed the third largest group (after serogroups B and C) among all Salmonella isolates [8]. The figures also considerably vary in the few studies carried out in the Gulf region. In Kuwait, the most prevalent was serogroup B, followed by serogroup C and D [12]. In Saudi Arabia, the most isolates were serogroup $\mathrm{D}$, followed by serogroup B and C [1]. The vast majority (>90\%) of Salmonellae isolated from man in developed countries belonged to serogroups $\mathrm{B}$ and $\mathrm{D}[16]$.

Like our study, a survey of 661 Salmonella isolated from Kuwait showed that resistant strains were more prevalent among children than adults [12]. A study carried out in Mérida, Venezuela, reported that $81 \%$ of the non-typhoidal Salmonella isolates were resistant to at least one of the antimicrobial tested [17]. A study from Thailand reported that most isolates were multidrug resistant [10]. Non-typhoidal Salmonella isolated in our study were sensitive to most antibiotics 
tested (71\%). The notable exceptions were Ampicillin (25\% resistant), Co-Trimaxazole (15\% resistant), and Chloramphenicol (8\% resistant). In Saudi Arabia, $50 \%$ of their Salmonella isolates were resistant to Ampicillin (except serogroup D 20\%), 15\% to Chloramphenicol (except serogroup C 50\%), and 5\% to Co-Trimaxazole [5]. A study carried out in Buenos Aires, Argentina, reported that all strains were resistant to Ampicillin, and 5.3\% to Chloramphenicol [18]. In Tunis, it was found that majority of Salmonella were isolated from blood and feces of newborns and nursing and Salmonella typhimurium represented $75 \%$ of the isolates, and all these isolates were resistant to Ampicillin and Chloramphenicol [19]. In Pontevedra, Spain, 39\% of the strains were resistant to Ampicillin [11]. In Kuwait, about 39\% of the isolate were resistant to Ampicillin, 17\% to Co-Trimaxazole, 13\% to Chloramphenicol [12]. In Yucatan, Mexico, resistance for the treatment of Salmonellosis was observed for Chloramphenicol (21\%), Co-Trimaxazole (19.3\%) and Ampicillin (17.6\%) [20]. While in Korea, all isolates were sensitive to Co-Trimaxazole [21]. The low resistance of our isolates to Ampicillin, Co-Trimaxazole and Chloramphenicol may need a separate study, however, better antibiotic prescribing practices at $\mathrm{Al}$ Ain Hospital may have some contribution.

In Belgium, all Salmonella strains were susceptible to Ceftriaxone and Ciprofloxacin [22]. In Spain, none of the strains was resistant to the 3rd-generation Cephalosporins and Fluoroquinolones [11]. In Kuwait, all the strains were susceptible to Ciprofloxacin [12]. A recent study from Seoul, Korea showed no resistance to Ciprofloxacin and Ceftriaxone [21]. In Yucatan, Mexico, none of the isolates was resistant to Ciprofloxacin, and only $0.8 \%$ resistant to Ceftriaxone [20]. In contrast, $5 \%$ of our Salmonella isolates were resistant to Ciprofloxacin and $2 \%$ were resistant to Ceftriaxone (only on Serogroup B).

\section{Conclusion}

Salmonella serogroups B, D and Salmonella spp. predominate as causative agent of gastroenteritis. Our findings prove those of earlier studies indicating that most non-typhoidal Salmonella strains were susceptible to a wide range of antimicrobial agents [8]. Nevertheless, antimicrobial resistance to clinically essential "first line" drugs is increasing among our isolates. This tendency is alarming and related to agricultural uses of antimicrobial agents [9].

Although most isolates remained susceptible, the first identification of ciprofloxacin and Ceftriaxone resistance in our isolates is a cause of concern. Active monitoring of non-typhoidal Salmonella for antibiotic resistance is crucial because of the public health implications derived from the increasing incidence of such organisms. There is also likelihood that incidence of invasive disease with non-typhoidal Salmonella can also increase in the future.

\section{Acknowledgments}

We thank all microbiology staff for their support.

\section{References}

1. Chart H (2002) Salmonella food poisoing; enteric fever. In: Greenwood D, Slack R, Peutherer J (Eds). Medical microbiology: A guide to microbial infections: Pathogenesis, immunity, laboratory diagnosis and control. (16thedn). Edinburgh: Churchill livingstone 250-259.

2. Mims C, Playfair J, Roitt I, Wakelin D, Williams R (1998) Medical microbiology. (2ndEdn); London: Mosby International Limited 257-259.
3. Volk WA, Gebhardt BM, Hammarskjöld M, Kadner RJ (1996) Essentials of medical microbiology. (5thedn); Philadelphia: Lippincott-Raven Publishers 370-373.

4. Trevejo RT, Courtney JG, Starr M, Vugia DJ (2003) Epidemiology of Salmonellosis in California, 1990-1999: Morbidity, mortality, and hospitalization costs. Am J Epidemiol 157: 48-57.

5. Al-Zamil FA, Al-Anazi AR (2001) Serogroups and antimicrobial susceptibility of non-typhoidal Salmonellas in children. Saudi Med J 22: 129-132.

6. Clinical and Laboratory Standards Institute (2005) Performance standards for antimicrobial susceptibility testing. Fifteenth informational supplement. CLSI document M100-S15. Wayne, PA, USA.

7. Darby J, Sheorey H (2008) Searching for Salmonella. Australian Family Physician 37: 806-810.

8. Chiu C, Su L, Hung C, Chen K, Chu C (2004) Prevalence and antimicrobial susceptibility of serogroup D nontyphoidal Salmonella in a University Hospital in Taiwan. J Clin Microbiol 42: 415-417.

9. Hohmann EL (2001) Nontyphoidal Salmonellosis. Clin Infect Dis 32:263-269.

10. Moolasart P, Sangsujja J, Eampokalap B, Ratanasrithong M, Likanonsakul S (1997) Nontyphoidal Salmonella diarrhea in Thai children: A study at Bamrasnaradura Hospital, Nonthaburi, Thailand. J Med Assoc Thai 80: 613-618.

11. Bellver P, Garcia M (2000) Epidemiology of non-typhoid Salmonellosis in a hospital in Pontevedra (1994-1997). Enferm Infecc Microbiol clin 18: 125-132.

12. Jamal WY, Pal T, Rotimi VO, Chugh TD (1998) Serogroups and antimicrobial susceptibility of clinical isolates of Salmonella species from a teaching hospital in Kuwait. J Diarrhoeal Dis Res 16: 180-186.

13. Kazemi M, Gumpert G, Marks MI (1974) Clinical spectrum and carrier state of nontyphoidal Salmonella infections in infants and children. CMA J 110: 1253-1257.

14. Dhanoa A, Fatt QK (2009) Non-typhoidal Salmonella bacteraemia: Epidemiology, clinical characteristics and its' association with severe immunosuppression. Ann Clin Microbiol Antimicrob 8: 15.

15. Köhler H (2009) Salmonellosis in young infants. Klin Padiatr 221: 54-56.

16. Old DC (1996) Salmonella. In: Collee JG, Fraser AG., Marmio, BP., and Simmons A (Eds) Mackie and McCartney practical medical microbiology. (14thedn); Edinburgh: Churchill Livingstone 385-404 .

17. Espinosa JA, Gonzalez JM, Andalia RC, Orozco LN (2009) Nontyphoid Salmonella gastroenteritis in pediatric patients from urban areas in the city of Mérida, Venezuela. J Infect Dev Coun 3: 28-34.

18. Maiorini E, Lopez EL, Morrow AL, Ramirez F, Procopio A, et al. (1993) Multiply resistant nontyphoidal Salmonella gastroenteritis in children. Pediatr Infect Dis J 12: 139-145.

19. Ben Hassen A, Bejaoui M, Hichri A, Lakhoua R, Ben Redjeb S (1993) Non-typhoid Salmonella in pediatric patients in Tunis (Hospital CharlesNicolle) from 1980-1991. Bulletin de la Société de pathologie exotique (1990) 86: 190-194.

20. Zaidi MB, McDermott PF, Fedorka-Cray P, Leon V, Canche, C, et al. (2006) Nontyphoidal Salmonella from human clinical cases, asymptomatic children, and raw retail meats in Yucatan, Mexico. Clin Infect Dis 42: 21-28.

21. Cheorg HJ, Lee YJ, Hwang IS, Kee SY, Cheong HW, et al. (2007) Characteristics of non-typhoidal Salmonella isolates from human and Broiler-chickens in southwestern Seoul, Korea. J Korean Med Sci 22: 773-778.

22. Van LM, Chasseur-Libotte ML, Godard C, Lammens C, Wijdooghe M, et al. (2001) Antimicrobial susceptibility of nontyphoidal Salmonella isolated from humans in Belgium. Acta Clin Belg 56: 180-186. 